\title{
HUBUNGAN SEJARAH KETATANEGARAAN DENGAN \\ PANCASILA
}

\author{
Wahyu Agus Aryanto ${ }^{1)}$,Luruh Dimas Fais ${ }^{2)}$,"Anita Trisiana ${ }^{3)}$ \\ ${ }^{1,2)}$ Mahasiswa Fakultas Pertanian Universitas Slamet Riyadi Surakarta \\ ${ }^{3)}$ Dosen Pancasila Universitas Slamet Riyadi Surakarta
}

\begin{abstract}
ABSTRAK
Sejarah konstitusional Republik Indonesia dimaksudkan sebagai bagian dari deskripsi ilmu hukum, kita akan dengan mudah mendapatkan kejelasan ketika kita pertama mempelajari sejarah negara, sehingga mempelajari sejarah ketatanegaraannya adalah mutlak perlu agar tidak terjadi dinamika atau salah paham.Melalui pendekatan historis, Sehingga kita tahu berbagai peristiwa dari waktu ke waktu di tanah air kita Republik Indonesia. Penelitian Deskriptif. jenis penelitian ini bertujuan menggambarkan mengenai klasifikasi suatu fenomena sosial, atau menjadi acuan pemecah suatu permasalahan dengan menjelaskan keadaan penelitian Dengan pendekatan sejarah diharapkan mendapat bahan bahan yang cukup tentang pancasila sebagai modal pokok yang akan dikembangkan lebih lanjut dalamhidup bangsa pandangan hidup juga sebagai dasar negara filsafat. Pancasila adalah rumusan dan pedoman bagi kehidupan berbangsa dan bernegara bagi seluruh penduduk Republik Indonesia, dengan mempertimbangkan sejarah dan mengkaji ulang akan dapat disimpulan bahwa pancasila merupakan dasar negara atau sering disebut juga dasar falsafah demikian pancasila digunakan untuk mengatur seluruh administrasi negara yang sudah tercantum atau terdapat didalam sila - sila pancasila, dari sila kesatu sampai kelima tercantum nilai - nilai Ketuhanan, Kemanusiaan, Persatuan, Kerakyatan, Keadilan.
\end{abstract}

Kata Kunci : Sejarah Ketatanegaraan, Dasar Negara. 


\begin{abstract}
The constitutional history of the Republic of Indonesia is intended as part of the description of law science, we will easily get clarity when we first study the history of the state, so that studying the history of its constitution is absolutely necessary so that dynamics or misunderstandings do not occur. Through the historical approach, so that we knowvarious events that have occurred from time to time in our homeland of the Republic of Indonesia. With a historical approach it is expected to get enough materials about Pancasila as the main capital that will be further developed in living the nation's view of life as well as the basis of state philosophy. Pancasila is a formula and guideline for the life of the nation and state for the entire residents of the Republic of Indonesia, by considering history and reviewing, it can be concluded that the Pancasila is the basis of the state or is often referred to as the basis of the state philosophy, so Pancasila is used as a basis for regulating all state administration that has been listed or contained in the precepts of Pancasila, from the first to fifth precepts listed the values of divine, humanity, unity, representatives, justice.
\end{abstract}

Keywords : constitutional history, National principle.

\title{
PENDAHULUAN
}

Dapat dikatakan bahwa
sejarah ketatanegaraan adalah
tonggak atau bahan-bahan untuk
mengevaluasi suatu permasalahan
dari waktu ke waktu agar kedepan
tercipta tatanan negara yang baik.
Karena sejarah tidak dapat
dipisahkan dari kehidupan rakyat
indonesia, dengan sejarah dapat
tercipta pikiran-pikiran atau ide-ide


muda agar tidak melupakan sejarah kelak kemudian hari dapat menjadi pelajaran untuk menjadikan bangsa indonesia menjadi bangsa yang makmur, maju, dan sejahtera. Semuannya itu tidak akan tercapai atau sia-sia apabila peran orang tua maupun sekolah tidak memberi bimbingan atau pembelajaran sejak dini mengenai sejarah bangsa indonesia, sehingga peran orang tua maupun sekolah itu sangat penting dalam mendidik anak muridnya, yang berarti sekolah adalah pendidiknya yaitu guru, jadi sekolah harus memberi ilmu atau pembelajaran mengenai sejarah bangsa indonesia lewat guru pendidik yang mempunyai gagasan atau ide untuk memberi ilmu yang bermanfaat bagi anak didiknya, misalnya dengan memberi pelajaran sejarah dan pendidikan kewarganegaraan.

Mengenai pandangan hidup juga tidak lepas dari sejarah bangsa indonesia. Dengan adanya pandangan hidup dapat dijadikan sebagai pedoman dan petunjuk hidup karena hasil dari pemikiran manusia bedasarkan pengalaman sejarah bangsa, setiap warga negara atau masyarakat mempunyai penentu masa depan, pandangan hidup tidak timbul dalam waktu yang singkat, tetapi harus melalui proses terlebih dahulu, sehingga dengan adanya pandangan hidup bangsadalam melangkah akan mudah.

Sedangkan dasar negara
adalah pondasi utama dalam
membentuk suatu negara ialah
sumber dari segala sumber hukum,
merupakan landasan kehidupan
bernegara dimana setiap negara
pastimemiliki landasan untuk
menjalankan kehidupan negaranya.

\section{METODE}

Dalam penelitian ini digunakan tipe Penelitian Deskriptif. jenis penelitian ini bertujuan menggambarkan mengenai klasifikasi suatu fenomena sosial, atau menjadi acuan pemecah suatu permasalahan dengan menjelaskan keadaan penelitian.

Menurut Sugiono (2005: 21) Menyatakan bahwa metode Deskriptif adalah suatu metode yang 
dapat digunakan untuk menggambarkan suatu hasil penelitian tetapi tidak digunakan untuk memuat kesimpulan yang lebih luas.

\section{PEMBAHASAN}

Pengertian dari Sejarah Ketatanegaraan, Pedoman Hidup, Dasar Negara :

1. Sejarah

Sejarah tercipta karena adanya suatu permasalahan yang terjadi pada masa lalu, sejarah dapat memberi gagasan atau ide untuk memberi informasi dan pengalaman serta tindakan yang harus kita ambil. Untuk kedepanya bisa menjadi tonggak keberhasilan dalam mengambil tindakan.

\section{Ketatanegaraan}

Seperangkat prinsip dasar yang mencakup susunan pemerintahan, bentuk negara dan sebagai dasar peraturan suatu negara.

3. Pedoman hidup

Sebuah hasil pemikiran yangdiakui kebenarannya. Kemudian atas dasar pemikiran ini manusia menggunakannya sebagai pedoman dan petunjuk dalam kehidupannya.

Juga dapat diartikan sebagai pertimbangan pendapat yang diperoleh dari hasil pemikiran manusia berdasarkan pengalaman sejarah yang dapat digunakan sebagai petunjuk hidup di dunia.

\section{Dasar Negara}

Dasar negara adalah pondasi utama dalam membentuk landasan kehidupan dalam bernegara. Pancasila adalah alat untuk mempersatu bangsa.Adanya dasar negara dapat menjadi acuan dan tujuan dalam bernegara.

\section{PENUTUP}

\section{Kesimpulan}

Bedasarkan pembahasan diatas dapat disimpulkan bahwa hubungan sejarah ketatanegaraan dengan pancasila merupakan hasil evaluasi sejarah dari waktu ke waktu agar tercipta tatanan negara yang baik. Karena sejarah tidak dapat dipisahkan dari kehidupan rakyat indonesia, dengan sejarah dapat 
tercipta pikiran-pikiran atau ide-ide baru untuk membentuk suatu aturan.

\section{Saran}

Bedasarkan kesimpulan tersebut dapat diajukan saran sebagai berikut:

\section{Bagi generasi muda}

Jangan pernah melupakan sejarah bangsa indonesia. Karena pemuda adalah tulang punggung negara, supaya kelak menjadi pribadi yang berguna.

2. Bagi masyarakat

Diharapkan masyarakat tidak melupakan pembelajaran sejarah dan diharapkan menjadi orang yang lebih baik serta dapat meniru tokoh-tokoh pahlawan jaman dahulu yang dapat dicontoh adalah tingkah lakunya dan kewibawaanya.
Serta senantiasa mengoreksi kinerja pemerintah agarkedepan tercipta tatanan keadilan yang merata.

3. Bagi pemerintah

Diharapkan dengan adanya sejarah masa lalu pemerintah bisa menjadikan pedoman untuk mengatur atau menjalankan pemerintahan dengan sebaik mungkin supaya terhindar dari suatu masalah dan kritik dari masyarakat. 


\section{DAFTAR PUSTAKA}

Ayu, Felisia Mega Sri, dan Trisiana,

A. (2017). Penguatan Pancasila Dalam Perbuatan (Alternatif Tindakan Kuratif Di Era Globalisasi). Jurnal Ilmiah, Vol. 4 No. 2, Pp. 1419.

Clinton L. Rassister, (1948). Constitutional Dictatorship. Princeton: Princeton University Press.

$\begin{array}{cr}\text { Ismaun,(1981). } & \text { Pembahasan } \\ \text { Pancasila } & \text { sebagai } \\ \text { Kepribadian } & \text { Bangsa } \\ \text { Indonesia. } & \\ \text { Bandung: Penerbit Yulanti }\end{array}$

Joeniarto, (1990). Sejarah Ketatanegaraan Republik Indonesia. Jakarta: Penerbit Bumi Aksara.
C.F.Strong, (1960). Modern Political Constitutions. London

Sidwick \& Jackson Limited, Fifth Edition - Second Impression.

Endah Agus Tiani, 2013. Generasi Muda Bicara Pancasila. Yogyakarta: Penerbit Ombak.

Godfrei Phillips, (1960). Constitutional Law, Printed in Great Britain. London \& Colchaster.

Sunoto, (1982). Filsafat Pancasila. Yogyakarta: Penerbit Hanindita.

Tanurdirjo, D.A. (2013). Generasi Muda Bicara Pancasila. Yogyakarta: Penerbit Ombak.

Zulkarnain, (2009). Pendidikan Sejarah.Yogyakarta: Jurnal Istoria Vol.7. No.1.09.(2009). 